\title{
Design alter egos: constructing and employing fictional characters in collaborative design sessions
}

\author{
George Triantafyllakos \\ Department of Informatics \\ Aristotle University of Thessaloniki \\ 54124, Thessaloniki, GREECE \\ gtrianta@csd.auth.gr
}

\author{
George Palaigeorgiou \\ Department of Industrial Informatics \\ T.E.I. Kavalas \\ 65404, Kavala, GREECE \\ gpalegeo@gmail.com
}

\author{
loannis A. Tsoukalas \\ Department of Informatics \\ Aristotle University of Thessaloniki \\ 54124, Thessaloniki, GREECE
}

tsoukala@csd.auth.gr

\begin{abstract}
The paper presents a novel approach to collaborative design of educational software with students, one that asks the participants for the formation and use of fictional characters design alter egos - as a means towards eliciting requirements and design ideas. In order to evaluate the suggested approach, we conducted 12 collaborative design sessions with the participation of 54 undergraduate university students (aged 19 to 24) for eliciting requirements for the design of an ideal course website. The analysis of the results showed that the design alter egos liberated the majority of the students from the fear of straightforwardly exposing themselves, supported and enhanced their introspection, stimulated their creativity and helped to establish an informal and constructive atmosphere throughout the design sessions. We suggest the use of design alter egos as an engaging and effective supportive technique for co-designing educational software with students.
\end{abstract}

\section{Keywords}

Design alter egos, fictional characters, scenarios, participatory design, collaborative design sessions, students.

\section{INTRODUCTION}

In user-centered and participatory design, the user and his needs become the central focus for both the designers and the design process. This commitment to the user is manifested through a tendency to replace existing task-oriented design approaches with user-oriented ones, a distinction similar to that between plot-centered or apsychological, and character-centered or psychological narratives [6]. The similarity between the two disciplines is not coincidental. The past few years, the discourse concerning the relationship between narrative (storytelling in general), interactivity, and design is undeniably noteworthy [23]. A significant part of this discourse concerns the use of fictional characters in design. Fictional characters have been used as user representatives, either substituting actual users or supporting idea generation. Their most common objective as design artifacts is to facilitate the identification of user needs and goals and support the creation of detailed and comprehensive scenarios.

(C) The Author 2009.

Published by the British Computer Society
Motivated by the aforementioned ongoing discourse and inspired by relevant approaches in the use of fictional characters in design, we aim at investigating the applicability and effectiveness of their use as a creative technique in collaborative design sessions. Our goal is to establish a design context where students are encouraged to search for new situated interactions supported by technology as opposed to mere technological solutions, understand and appreciate their internal motives, identify the causal links between them and their personality traits, and situate their design ideas and proposals in entrenched social behaviors. We present a novel approach, one that tries to surmount the difficulties that arise in existing approaches and is more appropriate for brief collaborative educational software design sessions with students.

After presenting the two most prominent approaches concerning the use of fictional characters in design, namely, those of personas and pastiche scenarios, we describe our approach and present a case study application. Eventually, we report our findings and discuss the strengths and weaknesses of our approach.

\section{FICTIONAL CHARACTERS IN DESIGN}

\subsection{Personas}

Personas as a user-centered design technique were introduced by Cooper [7] and have been widely used in design research and practice [e.g. 1, 5, 12, and 17]. They are considered as abstract representations of archetypal users that are developed based on real user data resulting from interviews, observations, field research and/or quantitative data analyses $[8,19]$ and they have been used as guides to the design process. They are fictional characters that embody unique users' characteristics, histories, thoughts and feelings [2] and which have precisely defined aspirations, needs and goals [1]. Personas work complementary to other design methods and techniques, primarily aiming at the creation of scenarios, and can greatly enhance their effectiveness [12]. They become a replacement of 'the user' throughout the design process, provide a shared language for communication between various stakeholders, allow designers to measure their designs' effectiveness, avert the risk of self-referential and/or elastic interpretations of 'the user' on behalf of the designers, and, eventually, act as an effective means towards committing design team members to the process [5, 7, 10, 19]. However, their most important benefit is that of being generative, allowing designers to easily project them in diverse contexts and situations and make inferences on their prospective behavior [12]. To achieve this though, personas have to be believable and as Nielsen [18] stated, they have to be represented as round characters, with 
multiple physiological and sociological traits, inner needs, motivations and interpersonal desires.

In Cooper's initial approach, actual users' participation in the design process is limited in providing appropriate data for the creation of the personas [1]. This practice however has been questioned and personas have been used by designers in flexible and creative ways [5]. For example, Johansson and Messeter [15] argue that constructing the personas, before any design actually takes place, constraints further development and exploration of "who the personas might be in different contexts". Instead, they propose an approach where exploration of the user becomes an integrated part of the design process, and thus, a way to reframe the design situation and allow for new ideas to emerge [15]. In another study, McGinn et al. [17] employed their clients' team early in the design process so as to define the most meaningful attributes of personas and subsequently conducted a survey to a larger collection of representatives focusing on those attributes in order to create their persona groups.

A weakness of the personas approach is that when they lack the necessary details that could render them as real, round characters [17] they could be reduced from user archetypes to user stereotypes [3]. As such they can lead to erroneous and superfluous assumptions and, eventually, mislead design decisions.

\subsection{Pastiche scenarios}

As an alternative to personas, pastiche scenarios propose the use of fictional characters from well-known cultural sources, such as literature, film, pop culture, etc. throughout participatory design processes [2]. Their overall goal is to provide design stakeholders with the ability to "explore alternative understandings of how different people might respond to proposed technologies" while offering "a space where personal and upsetting issues can be discussed in a distanced and safe way" [3].

Pastiche scenarios take advantage of the complexity and specificity in which fictional characters are described and also of people's tendency to strongly engage [12] and, at times, identify with them. Such characters can act as common denominators for all participants and reference points for further exploration of social, political or emotional contexts [2]. Furthermore, by introducing individual characteristics and behaviors in the design process it is claimed that design issues otherwise left unexamined can be brought to light [9].

However, pastiche scenarios do not come without problems. There is a difficulty for the designers to identify suitable characters, both familiar and engaging for the whole group of participants, especially when working with young participants [9]. Additionally, intense engagement with the fictional characters on behalf of the participants could lead to unfavorable, fruitless discussions where hilarity and fantasy prevail over productive design space explorations [9].

\section{DESIGN ALTER EGOS}

We introduce the idea of design alter egos. Design alter egos have been conceptualized as fictional characters. They are portrayals of representative users with a face, a name, a personality and a life story, but, instead of being based on user data analyses, as in the case of personas, they are created by the participants themselves at the initial stage of collaborative design sessions. Each participant creates his own design alter ego, forming his relevant to the design problem at hand physiological, psychological and sociological traits - all important dimensions for the development of a round character [18] - through a process of introspection, recollection and organization of personal experiences, and, at the same time, reflection on other user's attitudes and characteristics. He thus ends up with his own detailed and tangible rendering of 'the user', which becomes his communication agent throughout the design process, takes on his perspective and, eventually, plays at his role.

In the design context, the design alter egos assist each participant in establishing a comprehensive representation of 'the user' at the beginning of the design process, in a way similar to the establishment of a character in the first page of a film script [18]. Their construction aims at working as a warm up, preparatory technique forcing the participants to recall and shift all aspects of real users to their working memory and grab their attention. Design alter egos share several assumptions and benefits with personas and pastiche scenarios. Thus, similar to both approaches, they intend to be generative and used as a creative source of inspiration, allowing the participants to project them in different contexts and situations, and make assumptions on their prospective behavior [19]. Additionally, in a way not unlike that of pastiche scenarios, they aim at liberating the participants from the fear of straightforwardly exposing and talking about themselves during the design process [3].

Overall, our hypothesis is that design alter egos can provide each participant in a collaborative design session with a 'subject-to-think-for' and an 'object-to-think-with'. The former links back to the concept of 'the user' seen through the inevitably subjective but representative perspective of each individual participant. It is a fictional character with real features and with whom the participant will empathize, relate to and talk about. The latter refers to the tangible representation of this character as a boundary object $[4,13,14,21]$; an engaging mediating artefact facilitating the establishment of a shared understanding and communicating each participant's notion of 'the user' both between the participants inside a design session, and between the participants and the designers. As such, we consider design alter egos to be a technique that can intensify the participation experience and engagement, and increase the effectiveness of diverse collaborative design approaches.

\section{METHODOLOGY}

In order to evaluate the design alter egos technique, we conducted 12 collaborative design sessions with the participation of 54 undergraduate students with the goal of eliciting requirements for the design of an ideal course website. The process followed in the design sessions was structured and influenced by the requirements elicitation phase of the We!Design methodology [22]. Twenty-six (48\%) of the students were female and 28 were male (52\%). Students' registration in the design sessions was voluntary and was conducted through the use of a web-based registration system; hence, group synthesis was not controlled.

\subsubsection{Participants, settings and process description cards}

Each design session lasted for approximately 2 hours and 30 minutes and was comprised of four to six students and two coordinators. The coordinators were assigned the role of guiding the students throughout the design process and providing support when needed. One of the coordinators had a deep understanding of the educational processes involved and 
ensured that the students' proposals do not run contrary to commonly-accepted pedagogical norms and educators' or other stakeholders' interests [22]. The second coordinator was responsible for documenting students' needs, problems and design ideas. All participants sat around a table and were provided with the necessary worksheets.

So as to familiarize with the design process and support idea generation, students were provided with a set of 23 printed hand-sized cards (see Figure 1). The cards were divided in 4 categories corresponding to the 4 consecutive and discrete phases of the process: the introductory cards (6), the design alter ego creation cards (9), the design space exploration cards (6), and the evaluation cards (2). The cards played a dual role: (a) they acted as a guide for the students, directing them to the different stages of the design process, thus, making it easier for the coordinators to maintain and control the flow of the session, and (b) acted as visual (through their graphic design and pictures) and textual (through their descriptions) stimuli to support students cognitive processes and creativity when needed.

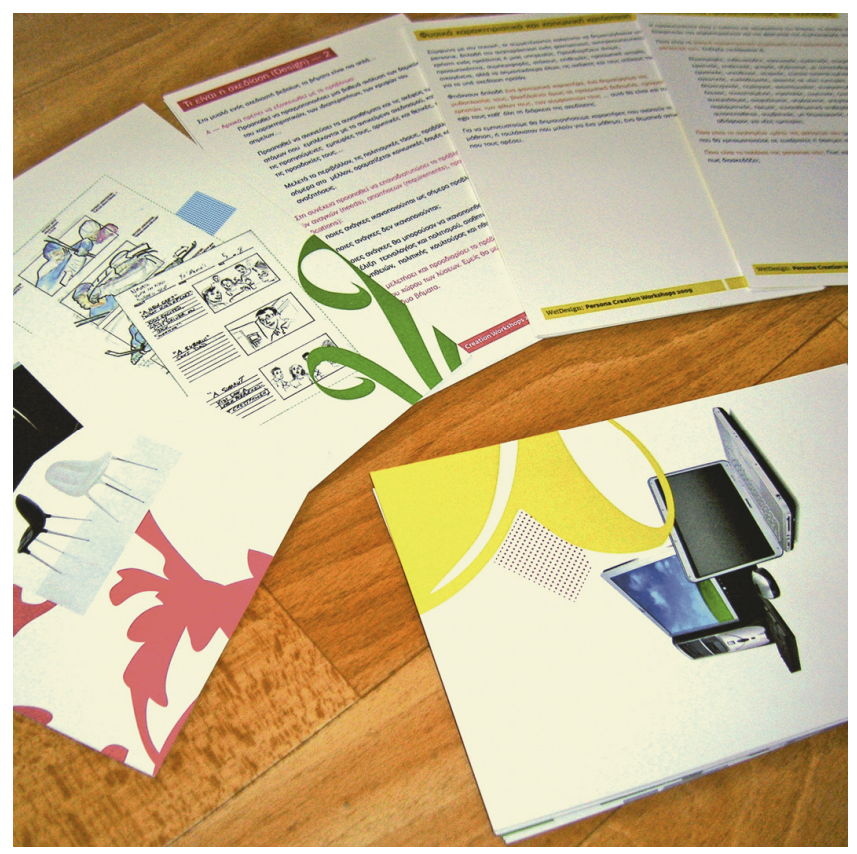

Figure 1. The process description cards

\subsubsection{Introductory phase}

During the introductory phase the students got acquainted with the design process and the problem at hand. The overall goals of the process were presented, followed by a short presentation of the basic principles of design and participatory design in particular. The coordinators tried to establish a common understanding between the participants that design is not merely a trendy and artistic endeavor, but a rather disciplined and structured enterprise that deals with wicked, open-ended problems and consists of a series of laborious, analytic activities. A detailed description of the design problem at hand followed, namely, the design of an ideal course website. The main challenge set was the envisioning of a course website that meets students' learning particularities, incorporates and sustains technological trends such as social networking and blogging, and which can be harmoniously situated in the daily routine of a modern, active student with multiple interests. The introductory phase's duration was approximately 15 minutes.

\subsubsection{Constructing the design alter egos}

Upon completion of the introductory phase the design alter egos concept was introduced. It was imperative to elaborate on the basic psychological assumption behind their conceptualization: that all people share a strong ability to envision one's behavior and thoughts while knowing little of him [19]. To demonstrate this innate ability, the coordinators asked students (a) to talk about fictional characters from well known TV series and project them in new situations, and (b) describe the personality of one of the coordinators by selecting from a list of indicative personality traits, even though they knew and heard him talk only for a few minutes. Both tasks were intriguing and effortless.

Students were then asked to play the role of a scriptwriter and develop their own design alter ego, for whom they will be asked to create scenarios during the rest of the design process. It is important to note that the coordinators used the term 'fictional character' throughout the design process instead of 'design alter ego' so as to avoid any indirect guidance or misconceptions derived from the familiar term alter ego that would confuse or constrain students in conceiving their characters. It was explained to them that their fictional character should (a) refer to a student, preferably close to their age, and (b) be someone with whom they can either relate to or simply be able to talk about. Both guidelines were emphasized as important prerequisites for the creation of their design alter egos since they could have a great affect on their ability to empathize and reflect on their behavior. No gender constraints were applied and the participants were encouraged to think beyond any stereotypical restrictions.

Each student was given a Fictional Character Form (see Figure 2 ), a specially designed work sheet with clearly separated areas containing text fields to be filled up by them (available at http://ierg.csd.auth.gr/we!design/files/alterEgoFormEng.pdf).

The areas referred to discrete characteristics of the design alter ego's personality and life style and were selected so as to cover a wide range, but relevant to the design problem, sociological attributes and personality traits. The whole set of attributes aimed at the creation of a round character [6, 18], allowed students to illuminate the details of their fictional character's personality and clarified the value system that governed its decisions, preferences and behavior:

(a) Photograph. Students initially had to select their character's photograph. The coordinators presented to the students a set of photographs depicting people close to their age which they had selected from a variety of cultural magazines. All photographs depicted every day, common people and had a balanced ratio of background, body and face characteristics, leaving students with an open space for interpretations [24]. Photographs of famous people and stock photos were not used. The coordinators asked students to select the one with which they can empathize the most. Afterwards, each student glued his selected photograph to the upper left corner of the Fictional Character Form.

(b) Name and age. A name and an age were requested for their fictional character.

(c) Favorite motto. This element provided students with the opportunity to envision their character's standpoint towards life, and, thus, engage with him in a more personal level.

(d) Basic personality traits. Students had to describe their characters' personalities selecting adjectives from a set 
extracted from the Ten-Item Personality Inventory [11] (e.g. extroverted, critical, anxious, enthusiastic, open to new experiences, etc).

(e) Academic status and ambitions/Professional ambitions. Since the fictional characters had to be students, this area of the form asked for information regarding their academic status, such as average grade, year of study, expected time of graduation etc. An important field for the rest of the design process was the list of favorite courses. The designed website should eventually support those courses. Finally, their academic and professional goals and ambitions were requested.

(f) Technological skills and habits. A number of technology related choices were provided. They included: everyday technology, that is, products used in an everyday routine (mobile, palmtop, notebook, etc.), most desirable technological product, computer/web/web2.0 level of knowledge, favorite computer applications and common tasks performed daily in the computer.

(g) Daily routine vs. extreme habits. A small description of the design alter ego's every day schedule was asked. Again, in order to evoke students' engagement, they had to describe the most extreme and out of the ordinary activities or desires of their design alter ego.

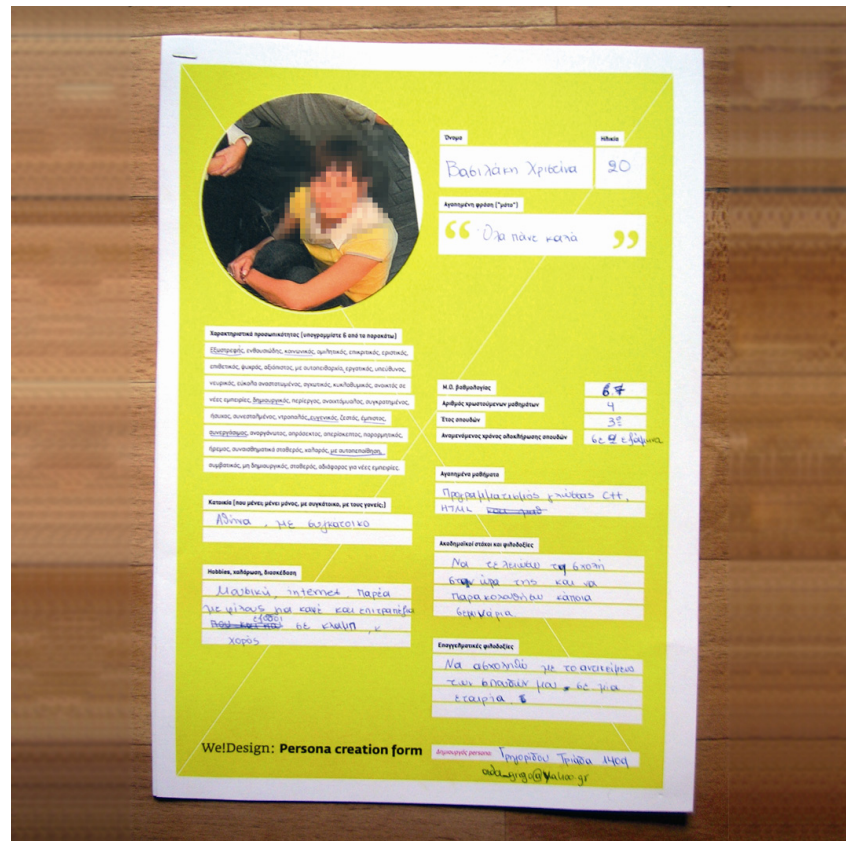

Figure 2. Example of a Fictional Character Form.

Each one of these elements was supported by a corresponding card with relevant pictures, descriptions, questions or explicit choices that inspired students while constructing their design alter egos. The students worked alone and referred to the corresponding cards whenever further support was needed.

When the students completed the creation of the design alter egos, they presented them to the rest of the group one at a time. They were asked to embody their design alter ego and use first person narrative in their presentations, as if they were actors playing at a role, in an effort to intensify emotional engagement [16]. The coordinators informed them that, for the rest of the process, each participant will be addressed using his design alter ego's name. This practice aimed at working as an equivalent of a cinematographic "suspension of disbelief"; a means towards sustaining the idea of the design alter ego in the minds of the students. During a presentation, the rest of the students asked clarifying questions or made remarks, while at the end of the presentation the coordinators asked questions about each design alter ego's behavior in extreme situations, so as to help the students start making coherent connections of the different attributed characteristics. When all presentations were completed, students placed their Fictional Character Forms in front of them in small transparent plastic stands, making them visible to them through the rest of the design process. The duration of this phase was approximately 30 minutes.

\subsubsection{Design space exploration}

The design space exploration constituted the core of the design process and its duration was close to one hour and 30 minutes. Its overall goal was the construction of scenarios describing instances of use of the course website by the students' design alter egos. The coordinators emphasized on incorporating identifiable causal relations between their scenarios and the characters' specific traits and motivations [18]. The process was organized in a structured way around the following five design activities. In each activity, students were asked to work alone at first and present their scenarios and discuss them with the rest of the group in the end. Two or more rounds inside each activity took place.

(a) Elicitation of existing problems and needs. Students were provided with a set of textual and visual stimuli, in the form of nouns, verbs, questions and photographs regarding the diverse contexts where their design alter egos could spend time during the course of a day. Exemplary text included phrases such as "in the morning, in the afternoon, at night" or "alone, with my roommate, with my family" etc., while exemplary imagery included photographs of a lecture room, a computer lab, a student's room etc. Then, they were asked to create scenarios of use of the course website in the specified contexts and highlight problems or needs that might come forth during its use. The goal of this activity was to help students recall and record existing problems and needs.

(b) Elicitation of design alter ego specific requirements. On the next activity students were asked to focus on their fictional character's specific personality traits and behavior and identify how these could relate to the use of the course website. Once again, students were provided with a set of relevant textual stimuli in the form of questions (e.g. "How would your design alter ego's academic ambitions affect the way she uses the course website?", "When would she use her favorite motto while using the course website?" etc.) The goal of this activity was to assist students in their search for well-situated needs, directly linked back to their design alter ego's individual characteristics.

(c) Search for new technological opportunities. Next, students were asked to situate their design alter ego in a context where advanced contemporary technology is the norm. Once again textual stimuli in the form of questions (e.g. "What kind of opportunities do Web2.0 technologies offer in the design of the course website for your design alter ego?") were provided, so as to think of opportunities that new technologies might offer.

(d) Design alter ego swapping. During this activity students were asked to swap their design alter egos 
with one another, together with their fictitious names, and perform another round of the activities (a), (b) and (c). The goal of this activity was to evoke a divergent way of thinking and stimulate students' imagination, by asking them to talk about someone they are less familiar with.

(e) Existing solutions' evaluation. Students were given back their design alter egos and were asked to evaluate existing solutions in relation to the problem at hand. In particular, they were given a set of printouts depicting existing course websites and learning management systems, and were asked to look for features or services that might be helpful for their design alter ego and that have not been mentioned during the previous activities. The goal of this activity was to incorporate known solutions to the design space exploration and motivate students to evaluate them critically through their design alter ego's perspective. Apparently, this activity had to be performed late in the process, so as not to inhibit or guide students' creativity throughout the design process.

(f) Imagining the future. During this last activity, students were presented with a 5-minute video comprised of segments from well-known Sci-Fi movies. The segments focused on the use of imaginary, futuristic technology and it was intended to act as stimulus that could once again help students think in a divergent way. They were asked to envision their design alter ego after 30 years in an imaginary setting and picture its life status (e.g. "What would her marital status be?"). They had to envision the ways in which the educational system or the social scenery might change and to seek for ways in which the new status quo would affect the requirements of the corresponding course website.

\subsubsection{Inquiry}

A video camera captured the design sessions' setting in order to provide a detailed documentation of the whole process and the implicit non-verbal interactions between the students. Additionally, after each session's completion, students were asked to evaluate the design process, the final products, their experience with the design alter egos, and the coordinators' role in a questionnaire containing 5-point Likert scales. Additionally, in the end of each session, coordinators initiated a brief semi-formal discussion concerning students' overall experience, so as to elicit their rational and critique of the process. The questions posed concerned their general satisfaction from the design approach, the justification of their character attributes, the similarity of the design alter ego with their personality, the effect it had on their creativity and the assessment of the final scenarios list.

\section{RESULTS}

Informal discussions were transcribed, and students' responses in the questionnaires together with the video recordings were thoroughly examined in order to identify issues and themes regarding the value of the design alter egos technique in the design process.

\subsection{Brief evaluation of the design process}

The participants could be considered as a representative sample of computer literate undergraduate students. Thus, they had extensive experience with the problem at hand, and they were able to recall relevant needs and ideas. They have been using computers for an average of 6.52 years, approximately 5 hours per day, sharing this time equally between academic work and personal interests.

Eighteen to twenty-eight (an average of 22) unique scenarios were produced in each design session, with each student suggesting 2 to 14 scenarios. The scenarios covered a wide range of requirements, including both typical needs already addressed in most learning management systems (such as providing news feeds, supporting team formation, making available video-recordings of the lectures) and innovative ideas (such as the integration of a course with relative job agencies, providing inter-university services for similar courses or presenting a course's history in the form of short documentaries).

We considered students' positive attitudes towards the session structure, the coordinators role and the design products as prerequisites for examining the effects of the design alter egos. As shown in Table 1, students' satisfaction with the design process was very positive (M: 4.60, S.D.: .48) as was their evaluation of the final list of scenarios (M: 4.31, S.D.: .59). Students believed that the suggested scenarios could eventually lead to the design of an original and particularly satisfying course website. Furthermore, they acknowledged that the coordinators did not interfere and did not influence their design suggestions (M: 4.57, S.D.: .68) and hence they could be considered as a neutral input in the design process.

Table 1. Students' evaluation of the design process

\begin{tabular}{lccc}
\hline & Mean & S.D. & Cr. $\mathbf{\alpha}^{*}$ \\
\hline Satisfaction with the design process (4 ques.) & 4.60 & .48 & .68 \\
\hline Satisfaction with the final products (3 ques.) & 4.31 & .59 & .64 \\
\hline Satisfaction with the coordinators' role (3 ques.) & 4.57 & .68 & .69 \\
\hline${ }^{*}$ Cronbach $\alpha$ & & &
\end{tabular}

Based on students' answers to the coordinators' informal questions and the video analysis, we could claim that the design process was a productive and engaging experience for all students. The cohesion of the design activities, the progressive exploration of the design problem and the managed demand for students' cooperation ensured students' overall satisfaction. Accordingly, the detailed way in which the setting was organized, the high quality and the diligence with which all the design artifacts (forms, cards, photographs, etc.) were provided seemed to establish students' confidence towards both the design process and the significance of their participation.

\subsection{Students' attitude towards the design alter egos}

The development and employment of the design alter egos were significant parts of the design process and hence students' positive attitudes towards the process indirectly referred back to those phases. In the end of all design sessions, students commented on these activities as being the most original, interesting and unanticipated. Their positive evaluation of the design alter egos' value was further supported by their responses to the corresponding questions in the technique evaluation questionnaire, shown in Table 2. 
Table 2. Students' attitude towards the design alter egos

\begin{tabular}{llc}
\hline & Mean & S.D. \\
\hline $\begin{array}{l}\text { The design alter ego was very helpful for the } \\
\text { exploration of the design space. }\end{array}$ & 3.70 & 1.04 \\
\hline $\begin{array}{l}\text { Without the design alter ego, I would have been more } \\
\text { creative. ( } r)\end{array}$ & 4.09 & .99 \\
\hline $\begin{array}{l}\text { Others' design alter egos influenced me positively. } \\
\text { I thought of fewer scenarios due to my design alter }\end{array}$ & 3.15 & 1.07 \\
$\begin{array}{l}\text { ego than if I talked directly about myself and my } \\
\text { needs. (r) }\end{array}$ & 3.52 & 1.22 \\
\hline $\begin{array}{l}\text { My design alter ego shares a lot of my personality } \\
\text { characteristics. }\end{array}$ & 3.80 & 1.12 \\
\hline $\begin{array}{l}\text { The design alter ego obstructed my thoughts several } \\
\text { times. }(r)\end{array}$ & 4.20 & 1.08 \\
\hline \begin{tabular}{l}
$r:$ reversed responses \\
\hline
\end{tabular}
\end{tabular}

\subsubsection{Constructing the design alter egos}

Although the Fictional Character Form was concise, students seemed rather motivated and willing to engage deeply in the exploration of their design alter ego's characteristics. In almost all design sessions, they asked for additional time to complete the form, to think, develop and empathy with their characters. The creation of the design alter ego initiated a form of introspection which forced students to inspect and recall several elements of their own personality, interests and habits. This effect was in accordance with our initial hypothesis of the value of using the design alter egos at the onset of the design process.

The majority of the students projected their own characteristics to their design alter egos ( 45 out of 54 students did not disagree with the statement "the design alter ego shares a lot of my personality characteristics"). They claimed that their design alter egos represented either an idealized version of themselves, an ideal partner (especially in the cases were they selected the photograph of a person of the opposite sex), or an intimate friend. In all cases, they shared many common characteristics with their design alter egos. Only few students experimented with extreme and divergent characteristics, while some of them created purely humoristic characters.

The selection of the photograph played a decisive role in the development of their fictitious characters. Several students stated that they were inspired by the physiological and style features of their selected photograph in order to envision their design alter ego's personality traits. This is in agreement with [24] and the observation that images of users are suggestive and trigger people's creativity. Thus, the selection of the photograph proved to be a rather intricate action, since in a very short period of time students had to project their stereotypical interpretations of external appearance, confront social desirability bias and expose themselves to the others through their choice. In all sessions students were curious to see their colleagues' choices. So as to make students feel less selfconscious of their selection, the coordinators humorously advised them to pick an image of a person that they "will not marry, will not hate, will not help accessorize", but simply "be able to talk on behalf of". Still, a few students made selections that were based on the distinctive features of the depicted individual and did not follow the coordinators' recommendations.

The students did not face any problems completing the rest of the Fictional Character Form. The process description cards offered students comprehensive guidance and sufficient support for each step of the process. Furthermore, they provided significant stimuli and supported their thinking during the diverse design activities. Several students commented on the cards' success. The students spent a lot of time developing the psychological and educational profile of their design alter ego while they completed the fields referring to her technological knowledge and habits rather easily.

\subsubsection{How the design alter egos affected students' participation}

The design alter egos' functioned as 'liberating agents' for the students, since they allowed them to consider themselves as not fully accountable for their proposals. This ascertainment was commonly accepted as one of the most crucial contributions of the technique to the process. The majority of the students felt free to explore new behaviours and ideas through the fictitious identity of their design alter egos, relieved from the burden of articulating their opinions straightforwardly and the fear of being criticized for them. This is further exemplified by the almost identical interpretations of the design alter egos, offered by the students in different design sessions:

"It's like talking about you, without actually talking
about yourself. And this makes it easier." "Apart from being a wall in front of you that helps you from exposing yourself, it's also something really interesting to work with."

"He protects you and allows you to say things that perhaps you wouldn't say about yourself. It's a kind of camouflage."

"I don't think that I could be so creative without Alice. It's different to see things through the eyes of someone else. It's sort of protecting you."

"Several characteristics are mine while others are not. I prefer though to work with Michael. Otherwise it's like playing The Moment of Truth - the TV game."

Additionally, the development of the design alter egos functioned as a warm up technique since students had to concentrate on their personal characteristics and then reintroduce themselves and socialize with their colleagues with their new identity from the very beginning of the design process. The fact that the coordinators addressed each student with his design alter ego's name helped maintain the informal and pleasant atmosphere during the design sessions.

Students needed some time to get used to the idea of speaking through their design alter egos. As one student stated "It was somewhat weird at the beginning, but then 'the ice broke!!" Eventually, all of the students engaged with their design alter egos to the point that, even several weeks after the completion of the design sessions, they entertain themselves by using their design alter egos' names in their conversations.

\subsubsection{How the design alter egos affected the scenario development process}

As shown in Table 2, students did not think of the design alter egos as an obstruction during scenario writing (M: 4.20, S.D.: 1.08). Instead, they found them to be rather helpful during the whole design process (M: 3.70, S.D.: 1.04) and considered them to be supportive to their creativity (M: 4.09, S.D.:.99). Several students stated that they wouldn't produce as many scenarios as they did without their design alter ego (M: 3.52, S.D.: 1.22).

The variance in the students' responses was related to the extent at which their design alter ego's personality resembled their 
own. When the resemblance was great, the design alter egos played a twofold role. They were used as a means of recalling personal problems, needs and preferences, and at the same time, they functioned as a creative source of inspiration offering supplementary fictitious characteristics to think for. The comments made by the majority of the students whose design alter egos shared similar characteristics with them, verify this argument:

"Sometimes Vicky helped me, sometimes she didn't. She brought some ideas to mind that I wouldn't suggest for myself but then I thought: yes, but she would like that."

"Irene helped me think more. Most of my ideas derived from her (even though I disagreed with her at several points)."

"Anna shares a lot of characteristics with me. However a lot of my ideas derived solely from her."

However, the students who developed design alter egos with whom they could not eventually empathize confronted many difficulties during the scenario development activities. They participated in the process by simply talking about themselves, or felt trapped in their creations and could not use them as a source of inspiration, or dismissed the whole design process and quietly abstained. In no such occasion did students state that their design alter egos affected them positively, while, at times, they became an impediment to their participation (a concise description of the corresponding design alter egos' personality is provided next to the following comments so as to exemplify the reasons that prevented the aforementioned students to empathize with them):

"Mine, just made my life difficult." [Ermolaos: a rather humoristic character, a lazy student not really interested in his studies, with his favorite motto being: "I will conquer the world"]

"My design alter ego was not close to my personality. It did not help me think more. I did not understand what Lazaros had to do with the course website. I found it easier to talk about my self." [Lazaros: another case of extreme character, with a tendency towards a wild, unconventional life style. Eventually the student who created him admitted that he made him too extreme to be someone he can relate to.]

This observation became more evident in students' responses to the technique evaluation questionnaire. The development of shared characteristics between the design alter ego and her creator correlated positively with the evaluation of the design process as being more helpful $(\mathrm{r}=.428, \mathrm{p}<.01)$, and negatively with the perceived potential creativity without the design alter ego $(\mathrm{r}=-.524, \mathrm{p}<.01)$ and the consideration of the design alter ego as an obstruction during the design process $(\mathrm{r}=-.297$, $\mathrm{p}<.05$ ). Furthermore, the resemblance of a design alter ego with her creator correlated positively with the overall satisfaction from the design process $(\mathrm{r}=.423, \mathrm{p}<.01)$ and the trust towards software applications designed in a corresponding way $(\mathrm{r}=.296$, $\mathrm{p}<.05)$ underlying once more the conditions of successful deployment of the design alter egos. We could cautiously claim that these results question the effectiveness of techniques such as personas or pastiche scenarios in participatory design circumstances where the participants have to engage with characters that they know little of or share few characteristics with. It is generally accepted that engagement and satisfaction with the design process are considered critical prerequisites for achieving effectiveness.
The design alter egos' effect on students' creativity was different during the various design space exploration activities. They worked effectively as generative devices during the first three design activities (elicitation of existing problems and needs, elicitation of design alter ego specific requirements, and search for new technological opportunities) allowing students to produce numerous diverse scenarios. Even though, students' evaluation on the helpfulness of their fellow students' design alter egos when swapping them was not high (M: 3.15, S.D.: 1.07), statistical correlation showed that this activity was evaluated more positively from the students who ascertain that the design process made them expend more cognitive effort $(\mathrm{r}=.331, \mathrm{p}<.01)$. We could claim that the students who tried to become acquainted with their fellow students' design alter egos were able to employ their characteristics creatively, while the rest developed a superficial relation to them and were unable to induce meaningful causal links for them.

The students' references to their design alter egos diminished as the design process progressed, namely during the last two design activities (existing solutions' evaluation and imagining the future). This behavior was to some extent expected. The aforementioned activities presented students with novel and unprecedented to them views of the design space. Consequently, students needed more time to recognize and comprehend the suggested approaches at first for themselves and then for their fictitious characters. The limited time prevented them from projecting their thoughts from their design alter ego's perspective. It is important to mention that, on the whole, these two design activities facilitated the production of only few scenarios.

Gender differences were also examined through independent samples t-tests on the technique evaluation questionnaire. The two genders were almost equally satisfied both from the design process and the products developed. However, as shown on Table 3, significant differences were identified in the evaluation of the design alter egos. Female students created more intimate fictitious characters and valued more the contribution of their design alter egos in their creativity. This finding is interesting and suggests that the technique is perhaps better suited to female participants. However, we cannot identify whether those differences originate from inherent feminine qualities regarding acting and empathy or they are the result of the development of more intimate fictitious characters. Further studies are required in order to understand the discrepancies and adapt the employment of the design alter egos technique accordingly.

\section{DISCUSSION}

Overall, students' evaluations revealed that the integration of the design alter egos technique in the collaborative design sessions was successful. Our initial hypotheses were supported given that the design alter egos liberated the majority of the participants from the fear of straightforwardly exposing themselves, supported and enhanced their introspection and helped to establish a creative atmosphere throughout the design sessions. The informal environment established by the coordinators, together with the coherent fashion in which the design process progressed provided an engaging experience for the students and allowed them to concentrate and benefit from their design alter egos. In particular, the design alter egos acted as 'tabula rasa' for the majority of the students to project upon them an idealized version of themselves together with characteristics and behaviors borrowed from others. This presented students with an opportunity to introspect and, in effect, re-invent themselves, while at the same time offered 
Table 3. Gender differences in students' evaluations

\begin{tabular}{|c|c|c|c|c|c|c|}
\hline & \multicolumn{2}{|c|}{ Male } & \multicolumn{2}{|c|}{ Female } & \multicolumn{2}{|c|}{ t-test } \\
\hline & Mean & S.D. & Mean & S.D. & $\mathbf{t}$ & $\mathbf{p}$ \\
\hline $\begin{array}{l}\text { The design alter ego was } \\
\text { very helpful for the } \\
\text { exploration of the design } \\
\text { space. }\end{array}$ & 3,46 & 1,07 & 3,96 & ,96 & - & - \\
\hline $\begin{array}{l}\text { Without the design alter } \\
\text { ego, I would have been } \\
\text { more creative. (r) }\end{array}$ & 3,79 & 1,07 & 4,42 & ,81 & 2,460 & $>0,01$ \\
\hline $\begin{array}{l}\text { Others' design alter egos } \\
\text { influenced me positively. }\end{array}$ & 3,00 & 1,16 & 3,31 & ,97 & - & - \\
\hline $\begin{array}{l}\text { I thought of fewer } \\
\text { scenarios due to my } \\
\text { design alter ego than if I } \\
\text { talked directly about } \\
\text { myself and my needs. (r) }\end{array}$ & 3,07 & 1,18 & 4,00 & 1,01 & 2,985 & $>0,01$ \\
\hline $\begin{array}{l}\text { My design alter ego } \\
\text { shares a lot of my } \\
\text { personality } \\
\text { characteristics. }\end{array}$ & 3,46 & 1,11 & 4,15 & 1,05 & 2,350 & $>0,05$ \\
\hline $\begin{array}{l}\text { The design alter ego } \\
\text { obstructed my thoughts } \\
\text { several times. (r) }\end{array}$ & 3,71 & 1,21 & 4,73 & ,60 & 3,851 & $>0,01$ \\
\hline
\end{tabular}

them a fruitful and stimulating source of inspiration. Students asserted that the design alter egos enhanced their creativity and, apart from only few exceptions, they did not perceive them as obstructions to the design space exploration.

We could claim that the design alter egos provide a more suitable technique for working with young students as opposed to personas and pastiche scenarios. In both approaches, participants are presented with existing characters, either based on real user data derived from diverse data analyses, as in the case of personas, or born from the imagination of an author/scriptwriter as in the case of pastiche scenarios. However, as described earlier, the resemblance of the majority of the students with their design alter egos correlated significantly with their overall satisfaction from the design process and their view of the design alter egos as creative stimulus. Thus, it could be supported that the identity of a fictional character plays a crucial role for the successful outcome of his employment in a collaborative design setting. As regards pastiche scenarios in particular, the difficulty in identifying suitable characters that are familiar and engaging to all participants becomes even more significant when working with young participants, a point also made by Dearden et al. [9]. Students' cultural references are extremely diverse and constantly changing, making it rather difficult to establish a consensus. Moreover, the sources of these cultural references are situated in ventures such as the contemporary music scene, mainstream filmmaking or television, with only few exceptions originating from literature or science, and certainly fewer from education. Consequently, they become irrelevant when the problem refers to the design of educational applications and it would be a rather laborious, if not impossible, task to incorporate them in the design process.

Eventually, it is imperative to underline that once again [22, 20] the students were excited with their participation in the design sessions, and they asserted that they would rely more on educational tools designed using such approaches. Students want a more determinative role in inventing their future learning and are available to participate, to be involved and contribute in addressing their needs. As a student commented "it was nice for once not to discuss using constantly 'T', 'me', 'mine'!" and as another critically stated "why shouldn't our ideas be put in place for once?" Short duration participatory design sessions provide a window to transform the imposed and externally determined reality of educational environments to a co-formulated desired prospect that embeds and respects students' diversity. For these reasons, the study of techniques that improve the experience and the effectiveness of the design process, such as the one presented in this paper, should be further continued.

In future applications of the design alter egos technique, we intend to continue investigating role-taking and character development based on narrative theory, along with their integration in collaborative design sessions [23]. Our goal is to gain a deeper understanding of the cognitive and affective processes that can influence students' experience with the technique and find ways to further augment their engagement with the design process, facilitate their participation, and enhance their creativity. Ultimately, we aim at verifying the hypothesis that the design alter egos technique can also be successfully employed in participatory design sessions with non-student participants, such as the elderly or young children, and in different design contexts, such as product or interaction design.

\section{REFERENCES}

[1] Blomquist, A., and Arvola, M. 2002. Personas in Action: Ethnography in an Interaction Design Team. In Proceedings of the 2nd Nordic conference on Humancomputer interaction (Aarhus, Denmark, 2002). NordiCHI'02. ACM, New York, NY, 197-200. DOI = http://doi.acm.org/10.1145/572020.572044

[2] Blythe, M., and Wright, P. 2006. Pastiche scenarios: Fiction as a resource for user centred design. Interacting with Computers. 18, 5 (September, 2006), 1139-1164. DOI $=\underline{\text { http: } / / \mathrm{dx} . \text { doi.org } / 10.1016 / \mathrm{j} . \text { intcom.2006.02.001 }}$

[3] Blythe M., and Dearden, A. 2008. Representing older people: towards meaningful images of the user in design scenarios. Universal Access in the Information Society. Published online: 6 June 2008. DOI $=$ http://dx.doi.org/10.1007/s10209-008-0128-x

[4] Brandt, E. 2005. How Tangible Mock-Ups Support Design Collaboration. Knowledge, Technology \& Policy. 20, 3 (October, 2007), 29-38. DOI = http://dx.doi.org/10.1007/s12130-007-9021-9

[5] Chang, Y., Lim, Y., and Stolterman, E. 2008. Personas: From Theory to Practices. In Proceedings of the 5th Nordic conference on Human-computer interaction: building bridges (Lund, Sweden, October 20 - 22, 2008). NordiCHI'08. ACM, New York, NY, 439-442. DOI = http://doi.acm.org/10.1145/1463160.1463214

[6] Chatman, S. 1978. Story and Discourse: Narrative Structure in Fiction and Film. New York, Cornell University Press.

[7] Cooper, A. 1999. The Inmates Are Running the Asylum. Sams.

[8] Cooper, A., Reimann, R., and Cronin, D. 2007. About Face 3: The Essentials of Interaction Design. Wiley.

[9] Dearden, A., Lauener, A., Slack, F., Roast, C., Cassidy, S. 2006. Make it so! Jean-Luc Picard, Bart Simpson and the Design of e-Public Services. In Proceedings of the Participatory Design Conference (Trento, Italy, August 1- 
5, 2006). PDC'06: Expanding Boundaries in Design. ACM Press, 67-76. DOI = http://doi.acm.org/10.1145/1147261.1147272

[10] Goodwin, K. 2001. Perfecting Your Personas. Retrieved Feb. 26, 2009, from http://www.cooper.com/journal/2001/08/perfecting_your personas.html

[11] Gosling, S.D., Rentfrow, P.J., and Swann, W.B. 2003. A very brief measure of the Big-Five personality domains. Journal of Research in Personality. 37, 6 (December 2003), 504-528. DOI = http://dx.doi.org/10.1016/S00926566(03)00046-1

[12] Grudin, J., Pruitt, J. 2002. Personas, Participatory Design and Product Development: An Infrastructure for Engagement. In Proceedings of the Participatory Design Conference (Malmo, Sweden, June 23-25, 2002). PDC'02. 144-161.

[13] Halskov, K., Dalsgaard, P. 2007. The Emergence of Ideas: The interplay between sources of inspiration and emerging design concepts. CoDesign. 3, 4 (December 2007), 185211. DOI $=$ http: $/ /$ dx.doi.org/10.1080/15710880701607404

[14] Johansson, M. and Linde, P. 2005. Playful collaborative exploration: New research practice in participatory design. Journal of Research Practice. 1, 1, Article M5 (2005).

[15] Johansson, M., and Messeter, J. 2005. Present-ing the user: constructing the persona. Digital Creativity. 16, 4 (2005), $231-243$. DOI $=$ http://dx.doi.org/10.1080/14626260500476606

[16] Kantola, V., Tiitta, S., Mehto, K., and Kankainen, T. 2007. Using Dramaturgical Methods to Gain More Dynamic User Understanding in User-Centered Design. In Proceedings of the 6th ACM SIGCHI conference on Creativity \& Cognition (Washington, DC, USA, June 13 15, 2007). C\&C'07. ACM, New York, NY, 173-181. DOI $=\underline{\text { http: } / / \mathrm{dx} . \text { doi.org } / 10.1145 / 1254960.1254985}$

[17] McGinn, J., Kotamraju, N. 2008. Data-Driven Persona Development. In Proceeding of the26th annual SIGCHI conference on Human factors in computing systems (Florence, Italy, April 05 - 10, 2008). CHI'08. ACM, New York, $1521-1524$. DOI = http://doi.acm.org/10.1145/1357054.1357292
[18] Nielsen, L. 2002. From user to character - an investigation into user-descriptions in scenarios. In Proceedings of the 4th conference on Designing interactive systems: processes, practices, methods, and techniques (London, England, June 25 - 28, 2002). DIS2002. ACM, New York, NY, 99-104. DOI = http://dx.doi.org/10.1145/778712.778729

[19] Pruitt, J. and Grudin, J. 2003. Personas: practice and theory. In Proceedings of the 2003 Conference on Designing for User Experiences (San Francisco, California, June 06 - 07, 2003). DUX '03. ACM, New York, NY, 1-15. DOI= http://doi.acm.org/10.1145/997078.997089

[20] Siozos P, Palaigeorgiou G., Triantafyllakos, G., Despotakis Th. 2008. Computer based testing using "digital ink": participatory design of a Tablet PC based assessment application for secondary education. Computers \& Education. 52, 4 (May 2009), 811-819. DOI $=\underline{\mathrm{http}: / / \mathrm{dx} . \mathrm{doi} . \text { org } / 10.1016 / \mathrm{j} . \text { compedu.2008.12.006 }}$

[21] Star, S.L., and Griesemer, J.R. 1989. Institutional ecology, "translations," and boundary objects: Amateurs and professionals in Berkeley's Museum of Vertebrate Zoology. , 1907-1939. Social Studies of Science.19, 3 (1989), 387-420. DOI = http://dx.doi.org/10.1177/030631289019003001

[22] Triantafyllakos, G. Palaigeorgiou, G., and Tsoukalas, I. A. 2008. We!Design: A student-centred participatory methodology for the design of educational applications. British Journal of Educational Technology. 39, 1 (January 2008), 125-139. DOI = http://dx.doi.org/10.1111/j.14678535.2007.00740.x

[23] Triantafyllakos, G., Palaigeorgiou, G., Tsoukalas, I. A. 2008. Collaborative Design as Narrative. In Proceedings of the 10th Participatory Design Conference (Bloomington, Indiana, USA, 1-4 October 2008). PDC'08. The Trustees of Indiana University, 210-213.

[24] Visser, F.S., and Stappers, P.J. 2007. Mind the face. In Proceeding of the 2007 conference on Designing Pleasurable Products and Interfaces (Helsinki, Finland, August 22 - 25, 2007). ACM, New York, NY, 119-134 DOI $=\underline{\text { http://doi.acm.org/10.1145/1314161.1314172 }}$ 